\title{
Electric Arc Smelting
}

\author{
CAMILLE FLEURIAULT, ${ }^{1,3}$ JOSEPH GROGAN,${ }^{1}$ and JESSE WHITE ${ }^{2}$ \\ 1.-Gopher Resource, Eagan, MN 55121, USA. 2.-Elkem Carbon AS, Kristiansand, Norway. \\ 3.-e-mail: Camille.Fleuriault@GopherResource.com
}

The vast majority of electric arc furnaces (EAFs) are used for steelmaking and production of ferroalloys. Other applications include processing of titanium concentrates, molybdenum, or various scrap metals. They are especially relevant to metals and alloys that have a high melting point, since these furnaces commonly reach temperatures above $2000^{\circ} \mathrm{C}$. EAFs operate under high vacuum or in an inert atmosphere. ${ }^{1}$ Scrap metal is typically melted with electrodes not contacting the metal, whereas immersed electrodes are used for smelting of ores and their concentrates in submerged arc furnaces (SAFs).

EAFs are used to produce carbon steel and alloys from steel scrap. Common feed sources also include pig, direct reduced, and hot briquette iron. In North America, EAF steelmaking accounts for $60 \%$ of production. ${ }^{2}$ These highly versatile furnaces are operated as batch reactors, with each cycle lasting from 35 min to more than 200 min. $^{3}$

EAFs are also widely applied for production of alloys from a wide range of feed sources. This topic starts with a contribution from Shuai Wang et al., who studied smelting of vanadium titanomagnetite (VTM). VTM is used to obtain vanadium pig iron, which is later converted to steel and commercial vanadium slag. ${ }^{4}$ Such ores are processed using blast furnaces and, most commonly, electric arc furnaces. Higher titanium content can significantly modify the slag properties, hindering slag-metal separation. During titanomagnetite processing, silicon exhibits the same behavior as titanium, making it a valuable tool for optimization of furnace conditions. A comprehensive study of the behavior of $\mathrm{Ti}$, $\mathrm{Si}$, and $\mathrm{V}$ in Fe slag phases was conducted by Wang et al. for application to direct reduction in electric furnaces. In "Behavior of Titanium during the Smelting of Vanadium Titanomagnetite Metallized

Camille Fleuriault, Joseph Grogan, and Jesse White are the JOM advisors for the Pyrometallurgy Committee of the TMS Extraction \& Processing Division, and guest editors for the topic Electric Arc Smelting in this issue
Pellets in an Electric Furnace," the authors perform an analysis of the $\mathrm{TiO}_{2}$ activity and the titanium distribution ratio between the molten phases. Thermodynamic analyses conducted using FactSage 7.0 showed that calcium, and to a lesser extent magnesium, promote formation of high-grade titanium slag. Laboratory-scale smelting experiments confirmed the results of the thermodynamic study and quantified the impact of the smelting temperature on the titanium content in the iron. In a second study, the authors conducted a complementary investigation on silicon. "Behavior of Silicon during the Reduction and Smelting of Vanadium Titanomagnetite Metallized Pellets in an Electric Furnace" shows that the activity of free oxygen ions and silicate is promoted by basic oxides such as $\mathrm{CaO}$ and $\mathrm{MgO}$, while silica activity is hindered by such oxides. These results were obtained both thermodynamically and experimentally in a laboratory-scale electric furnace, confirming the correlation between $\mathrm{Si}$ and Ti.

The second highlight of this topic is the production of ferrosilicon in EAFs. This carbothermic reduction process takes place in submerged furnaces, either open or covered, from quartz, charcoal, mill scale, and fluxes such as limestone. ${ }^{3}$ In "Effects and Electrical Resistance of Metallurgical Coke and Semicoke on Silicon Recovery in an Electric Arc Furnace," Hasannezhad and Meysami compare the properties of two types of coke using immersion testing and the ASTM G57 test for electrical resistance. The results show that the furnace efficiency is significantly greater when using semicoke, which has greater porosity and resistance. In such conditions, $\mathrm{SiO}_{2}$ gas transfer is promoted while the furnace energy consumption is decreased.

Energy consumption, in fact, is one of the main challenges associated with electric arc smelting. A modern EAF uses approximately $400 \mathrm{kWh}$ to produce 1 ton of steel. ${ }^{5}$ Depending on plant location, scrap type, and regional power availability, energy costs may represent a significant portion of a plant's operating expenses. Melting and holding processes 
can represent over $60 \%$ of the total energy requirements of a plant. ${ }^{2}$ Reducing this energy footprint has been the driving force behind many recent technological advances in the EAF domain, including preheating, heat conversion, and oxygen addition. Parsunkin et al. investigated a new electrical mode control in "Energy Saving Extremal Control of an Electrical Mode of Electric Arc Units." To maximize the performance of an EAF process, the authors calculated the dependences of the power, cost, and treatment time on various furnace operating parameters. They proposed an "automatic extremal control search system" to optimize the characteristics and hence the efficiency of the arc. A trial run of a 180-t EAF under extremal control showed 10-14\% less losses when using the search mode and confirmed its applicability to other iron and steel plants using EAF technology.

Another driver for recent technical milestones in electric arc smelting is environmental stewardship. More precisely, management of gases and solid waste such as slag or dust is one of the factors conditioning the development of this industry. Common sources of volatile organic compounds (VOCs), $\mathrm{SO}_{x}$, and $\mathrm{NO}_{x}$ are fluxes, electrode consumption, reducing agents, and feed contaminants; For instance, scrap metal contains up to $2 \%$ of paint, oil, or other organics. ${ }^{6}$ Airborne emissions are also significant, with up to $15-25 \mathrm{~kg}$ of dust being released per ton of steel produced in an EAF. Projection of liquid metal and slag has been identified as the main contributor to dust production. The high operating temperature of an EAF also favors release of volatile species such as zinc. The final paper of this topic, entitled "Airborne Emissions from Mn Ferroalloy Production" by Kero et al., presents a state-of-the-art review of currently available technologies for emission control in Mn ferroalloy production. In an effort to provide essential information to key industry players, the authors detail the sources, formation, and known control processes for greenhouse, $\mathrm{NO}_{x}$, and $\mathrm{SO}_{x}$ gases and polycyclic aromatic hydrocarbons, as well as sources and management of heavy metals, mercury, and particle matter.
The following papers are published under the topic "Electric Arc Smelting" in the January 2019 issue (vol. 71, no. 1) of JOM and can be accessed via the $J O M$ page at http://link.springer.com/journal/1 1837/71/1/page/1:

- "Behavior of Titanium during the Smelting of Vanadium Titanomagnetite Metallized Pellets in an Electric Furnace" by Shuai Wang, Yufeng Guo, Tao Jiang, Feng Chen, Fuqiang Zheng, Lingzhi Yang, and Minjun Tang

- "Behavior of Silicon during Reduction and Smelting of Vanadium Titanomagnetite Metallized Pellets in an Electric Furnace" by Shuai Wang, Yufeng Guo, Tao Jiang, Feng Chen, Fuqiang Zheng, and Lingzhi Yang

- "Effects of Porosity and Electrical Resistance of Metallurgical Coke and Semicoke on Silicon Recovery in an Electric Arc Furnace" by Hossein Hasannezhad and Amirhossein Meysami

- "Energy-Saving Extremal Control of an Electrical Mode of Electric Arc Units" by Boris N. Parsunkin, Maxim V. Uschev, Oxana S. Logunova, and Valentina V. Koroleva

- "Airborne Emissions from Mn Ferroalloy Production" by Ida Teresia Kero, Per Anders Eidem, Yan Ma, Hege Indresand, Thor Anders Aarhaug, and Svend Grådahl.

\section{REFERENCES}

1. F. Habashi, Electric arc melting, in Textbook of Pyrometallurgy (Metallurgie Extractive Quebec, Quebec, 2002), pp. 532-534

2. K.R. Haapala, A.V. Catalina, and J.W. Sutherland, J. Manuf. Sci. Eng. 134, 1 (2012).

3. EPA, Ferroalloy production, in Compilation of Air Pollutant Emissions Factors (AP-42) (2009) (pp. 1-20).

4. L.A. Smirnov, M.A. Tret'yakov, and V.I. Gladyshev, Metallurgist 44, 230 (2000).

5. J. Von Scheele, Scand. J. Metal. 28, 169 (1999).

6. M. Nakayama, and K. Hirotsugu, Progress of Emission Control System in Electric Arc Furnace Melt-Shops, NKK Technical Report-Japanese Edition.

7. C. Rizescu, C. Ittu, E.V. Stoian, D.N. Ungureanu, and Z. Bacinschi, Proceedings of the 2011 International Conference on Biomedical Engineering and Technology (Singapore) (2011), pp. 137-141. 